\title{
Adubação nitrogenada no consórcio de milho com duas espécies de braquiária em sistema plantio direto
}

\author{
Nídia Raquel Costa ${ }^{(1)}$, Marcelo Andreotti ${ }^{(1)}$, Roberta de Aquino Gameiro(1), Cristiano Magalhães Pariz ${ }^{(2)}$, \\ Salatiér Buzetti ${ }^{(1)}$ e Keny Samejima Mascarenhas Lopes ${ }^{(1)}$
}

\begin{abstract}
(1)Universidade Estadual Paulista Júlio de Mesquita Filho (Unesp), Faculdade de Engenharia, Campus de Ilha Solteira, Avenida Brasil, no 56, Centro, CEP 15385-000 Ilha Solteira, SP. E-mail: nidiar_costa@hotmail.com, dreotti@agr.feis.unesp.br, roberta_ag@hotmail.com, sbuzetti@agr.feis.unesp.br, keny.unesp.zoo@hotmail.com (2)Unesp, Faculdade de Medicina Veterinária e Zootecnia, Campus de Botucatu, Distrito de Rubião Jr., s/no, CEP 18618-970 Botucatu, SP. E-mail: cmpzoo@gmail.com
\end{abstract}

Resumo - O objetivo deste trabalho foi avaliar a produtividade de grãos e de forragem do consórcio entre milho e espécies de braquiária (safras de 2008/2009 e 2009/2010), submetidos a doses de nitrogênio em cobertura, em sistema plantio direto. Utilizou-se o delineamento experimental inteiramente casualizado, com quatro repetições, em arranjo fatorial 2x5, com duas espécies de braquiária (Urochloa brizantha 'Xaraés' e U. ruziziensis) e cinco doses de $\mathrm{N}$ aplicadas em cobertura: 0, 50, 100, 150 e $200 \mathrm{~kg} \mathrm{ha}^{-1}$. Foram avaliados: leituras indiretas do teor foliar de clorofila (índice de clorofila Falker, ICF), teores de macronutrientes foliares, componentes da produção e produtividade de grãos do milho, e produtividade de matéria seca das forrageiras após o consórcio. Constatou-se que a espécie $U$. ruziziensis foi a mais competitiva com o milho em consórcio, o que proporcionou menores teores nutricionais e ICF nas duas safras analisadas. $\mathrm{O}$ crescimento vegetativo, os componentes da produção e a produtividade de grãos do milho não foram influenciados pelos consórcios. A adubação nitrogenada em cobertura aumenta linearmente o ICF, os teores de N, P e S, bem como os componentes da produção e a produtividade de grãos.

Termos para indexação: Urochloa brizantha 'Xaraés', Urochloa ruziziensis, Zea mays, clorofila, integração lavoura-pecuária, nitrogênio.

\section{Nitrogen fertilization in the intercropping of corn with two Brachiaria species in a no-tillage system}

\begin{abstract}
The objective of this work was to evaluate grain and forage yield of the intercropping of corn with Brachiaria species (2008/2009 and 2009/2010 crop seasons), subjected to nitrogen topdressing rates in a no tillage system. A completely randomized block design was used, with four replicates, in a $2 \times 5$ factorial arrangement, with two Brachiaria species (Urochloa brizantha 'Xaraés' and U. ruziziensis) and five $\mathrm{N}$ topdressing rates: $0,50,100,150$, and $200 \mathrm{~kg} \mathrm{ha}^{-1}$. The following were evaluated: indirect readings of leaf-chlorophyll content (Falker chlorophyll index, ICF), macronutrient content in leaves, yield components and grain yield of corn, and forage dry mass yield after intercropping. It was observed that the species $U$. ruziziensis was more competitive with corn in intercropping, providing lower nutritional content and ICF in both evaluated seasons. Vegetative growth, yield components, and grain yield of corn were not affected by the intercrops. Nitrogen topdressing fertilization linearly increases the ICF, leaf contents of N, P and S, as well as the yield components and grain yield.

Index terms: Urochloa brizantha 'Xaraés', Urochloa ruziziensis, Zea mays, chlorophyll, crop-livestock integration, nitrogen.
\end{abstract}

\section{Introdução}

Atualmente, os sistemas de produção com integração agrícola podem ser classificados em quatro modalidades distintas: integração lavoura-pecuária (ILP) ou agropastoril, que integra os componentes agrícola e pecuário em rotação, consórcio ou sucessão, na mesma área e no mesmo ano agrícola ou por múltiplos anos; integração pecuária-floresta (IPF) ou silvipastoril, que envolve os componentes pecuário (pastagem e animal) e florestal, em consórcio; integração lavoura-floresta (ILF) ou silviagrícola, que integra os componentes florestal e agrícola pela consorciação de espécies arbóreas com cultivos agrícolas (anuais ou perenes); e integração lavoura-pecuária-floresta (ILPF) ou agrossilvipastoril, que incorpora os componentes agrícola, pecuário e

Pesq. agropec. bras., Brasília, v.47, n.8, p.1038-1047, ago. 2012 
florestal em rotação, consórcio ou sucessão, na mesma área (Balbino et al., 2011a, 2011b).

Nesse contexto, a ILP é definida, de acordo com Macedo (2009), como o conjunto de sistemas produtivos que buscam maior sustentabilidade na propriedade rural e que envolvem, em uma mesma área, a produção de grãos, consorciados ou não, com espécies forrageiras e a produção animal. Portanto, a semeadura das culturas pode ser realizada de forma simultânea, sequencial ou rotacionada, o que garante maior eficiência na utilização da área agrícola durante todo o ano, e melhor aproveitamento do maquinário disponível e do efeito residual de corretivos e de fertilizantes, o que melhora as condições sociais no meio rural, com diminuição dos impactos ambientais.

Assim, em diversas regiões do mundo, a recuperação de áreas degradadas, a redução dos custos de produção e o uso intensivo da área durante todo o ano estão sendo viabilizados pela ILP, em sistema plantio direto (SPD), com o cultivo de culturas graníferas ou de forragem e a pecuária, o que gera resultados socioeconômicos e ambientais positivos (Tracy \& Zhang, 2008; Pariz et al., 2009; Rufino et al., 2009; Crusciol et al., 2012).

Em áreas de lavoura com solos corrigidos, foi preconizado o sistema consorciado de culturas graníferas com forrageiras tropicais, principalmente as dos gêneros Panicum e Urochloa (Kluthcouski et al., 2000). De acordo com estes autores, esse consórcio apresenta grandes vantagens, pois, na maioria dos casos, pouco altera o cronograma de atividades do produtor rural, é de baixo custo e não exige equipamentos especiais para sua implantação. Esse sistema é opção vantajosa para produção de forragem do outono à primavera (Pariz et al., 2011b).

Como alternativa ao pastejo de animais, a forragem produzida após a colheita da cultura granífera pode ser ceifada mecânica ou manualmente (Pariz et al., 2011b), e ser utilizada para fenação, fornecimento em cocho, como componente volumoso na formulação de dietas de confinamento, ou armazenada na forma de silagem (Pariz et al., 2010), com posterior formação de palhada para continuidade do SPD (Pariz et al., 2011c). Outra opção é a realização do consórcio com vistas apenas à formação de palhada para as culturas do feijão (Silveira et al., 2005) ou da soja (Chioderoli et al., 2010). Porém, nesse caso, não se caracteriza ILP, e sim, SPD.

No consórcio de culturas graníferas com forrageiras, o conhecimento do comportamento das espécies na competição por água, luz e nutrientes torna-se de grande importância para o êxito da produtividade satisfatória de grãos e da formação de pastagem (Pariz et al., 2011a). Nesse aspecto, o estudo da adubação nitrogenada é de suma importância, uma vez que, apesar dos benefícios do efeito residual das adubações fosfatada e potássica na ILP (Martha Júnior et al., 2009), nos primeiros cinco anos sob SPD, a exigência de nitrogênio é alta em função da imobilização desse nutriente na palhada das culturas (Anghinoni, 2007).

O emprego de medidor portátil de clorofila, equipamento que permite medições instantâneas do índice de clorofila foliar (SPAD ou ICF), constitui alternativa promissora para avaliação do teor de nitrogênio nas plantas, o que possibilita o manejo mais eficiente da adubação nitrogenada (Rambo et al., 2008). As razões para isso são: a leitura pode ser realizada em poucos segundos; o aparelho tem custo mínimo de manutenção, ao contrário de outros testes que exigem compra sistemática de produtos químicos; não há necessidade de envio de amostras para laboratório; e podem ser realizadas quantas amostragens forem necessárias, sem destruição de folhas (Malavolta et al., 1997). Contudo, ainda são escassos os estudos sobre índices em consórcios de culturas graníferas com forrageiras, em que a necessidade de nitrogênio na fase inicial é alta, em razão da competição por esse nutriente.

O objetivo deste trabalho foi avaliar a produtividade de grãos e de forragem do consórcio entre milho e espécies de braquiária, submetidos a doses de $\mathrm{N}$ em cobertura, em sistema plantio direto.

\section{Material e Métodos}

O experimento foi conduzido nos anos agrícolas de 2008/2009 e 2009/2010, na Fazenda de Ensino, Pesquisa e Extensão, pertencente à Faculdade de Engenharia, Campus de Ilha Solteira, área de produção vegetal, localizada no Município de Selvíria, MS (2020'05"S e 5124'26"W, a $335 \mathrm{~m}$ de altitude). O clima da região, segundo a classificação de Köppen, é do tipo Aw, caracterizado como tropical úmido, com estação chuvosa no verão e seca no inverno.

A área experimental, no momento da instalação do experimento, encontrava-se em sistema plantio direto há oito anos, com culturas anuais e perenes, para formação de palhada, sendo a cultura anterior de feijão de inverno, para os dois ciclos avaliados. A área foi 
irrigada por aspersão (pivô central), quando necessário, em função de deficits hídricos, durante todo o período experimental. Na Figura 1, estão apresentados os dados de precipitação pluvial e de temperatura no período experimental.

O solo da área é um Latossolo Vermelho distroférrico (Santos et al., 2006). Os atributos físicos e químicos, anteriormente à instalação do experimento (ano agrícola de 2008/2009), na camada de 0 a 0,20 m do solo, indicaram: densidade do solo de $1,31 \mathrm{~kg} \mathrm{dm}^{-3}$; macro, micro e porosidade total de $0,147,0,334$ e $0,481 \mathrm{~m}^{3} \mathrm{~m}^{-3}$, respectivamente; $\mathrm{pH}$ em $\mathrm{CaCl}_{2}$ de 5,1;28 $\mathrm{g} \mathrm{dm}^{-3}$ de $\mathrm{MO}$; 22,2 $\mathrm{mmol}_{\mathrm{c}} \mathrm{dm}^{-3} \mathrm{de} \mathrm{H}+\mathrm{Al} ; 18 \mathrm{mg} \mathrm{dm}^{-3}$ de P-resina; 3,2, 19 e $11 \mathrm{mmol}_{\mathrm{c}} \mathrm{dm}^{-3} \mathrm{de} \mathrm{K}^{+}, \mathrm{Ca}^{2+} \mathrm{e} \mathrm{Mg}^{2+}$, respectivamente; e $59,9 \%$ de V. Na safra de 2009/2010, os atributos referentes à fertilidade do solo, também na camada de 0 a 0,20 m de profundidade, indicaram: $\mathrm{pH}$ em $\mathrm{CaCl}_{2}$ de 5,0; $27 \mathrm{~g} \mathrm{dm}^{-3}$ de $\mathrm{MO} ; 33,9 \mathrm{mmol}_{\mathrm{c}} \mathrm{dm}^{-3}$ de $\mathrm{H}+\mathrm{Al}$; $15 \mathrm{mg} \mathrm{dm}^{-3}$ de P-resina; 2,2, 19,7 e 12,5 $\mathrm{mmol}_{\mathrm{c}} \mathrm{dm}^{-3} \mathrm{de}$ $\mathrm{K}^{+}, \mathrm{Ca}^{2+}$ e $\mathrm{Mg}^{2+}$, respectivamente; e $50 \%$ de V.

Utilizou-se o delineamento experimental em blocos inteiramente casualizados, com quatro repetições, em arranjo fatorial $2 \times 5$. Os tratamentos consistiram em: consórcio da cultura do milho (híbrido simples DKB 390 YG) com duas espécies de braquiária [Urochloa brizantha 'Xaraés' (Syn. Brachiaria brizantha 'Xaraés') e U. ruziziensis (Syn. B. ruziziensis)], adubados em cobertura com quatro doses crescentes de nitrogênio, na forma de ureia, mais a ausência de adubação $(0,50$, 100,150 e $\left.200 \mathrm{~kg} \mathrm{ha}^{-1}\right)$.

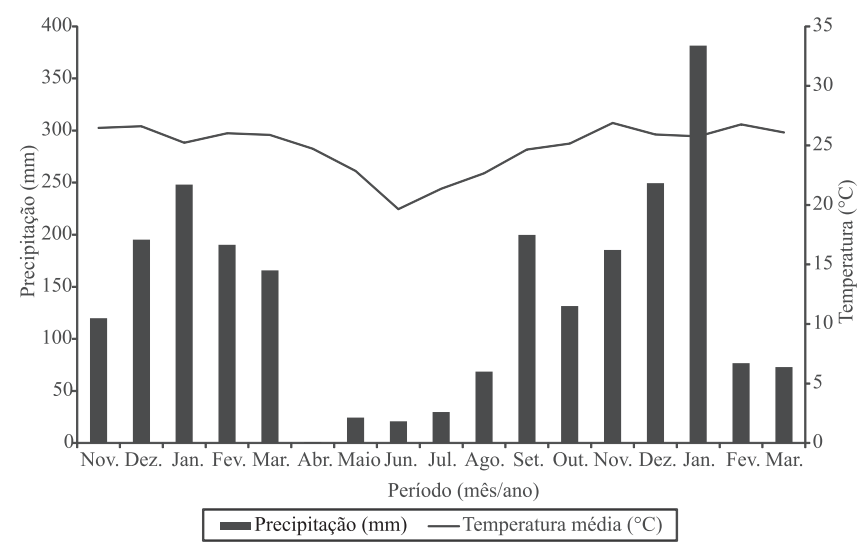

Figura 1. Precipitação pluvial e temperatura média mensal, no período de novembro de 2008 a março de 2010, obtidos junto à estação meteorológica situada na Fazenda de Ensino, Pesquisa e Extensão, da Faculdade de Engenharia, da Unesp, em Selvíria, MS.
A área experimental totalizava $1.440 \mathrm{~m}^{2}$, com parcelas de $36 \mathrm{~m}^{2}$, constituídas por quatro linhas de milho $(3,6 \mathrm{~m})$ com $10 \mathrm{~m}$ de comprimento. Para as avaliações dos componentes da produção e da produtividade de grãos do milho, foram consideradas duas linhas centrais, tendo-se desprezado $1 \mathrm{~m}$ em cada extremidade.

Antes da semeadura do milho na safra de 2008/2009, a área foi dessecada com herbicida glifosato na dose de $1.440 \mathrm{~g}$ i.a. ha ${ }^{-1}$. A cultura do milho foi semeada mecanicamente por meio de semeadora-adubadora, com mecanismo sulcador tipo haste (facão), para SPD, em 18/11/2008, a uma profundidade de aproximadamente $0,05 \mathrm{~m}$, com espaçamento de $0,90 \mathrm{~m}$ e 5,4 sementes por metro, para atingir estande final de 55.000 a 60.000 plantas por hectare. Foi realizada adubação de semeadura no milho com aplicação de $24 \mathrm{~kg} \mathrm{ha}^{-1}$ de N, $84 \mathrm{~kg} \mathrm{ha}^{-1}$ de $_{2} \mathrm{O}_{5}$ e $48 \mathrm{~kg} \mathrm{ha}^{-1}$ de $\mathrm{K}_{2} \mathrm{O}$ (300 kg ha-1 do formulado 08-28-16). As sementes de milho foram tratadas com $150 \mathrm{~g} \mathrm{~L}^{-1}$ i.a. de imidacloprido $+450 \mathrm{~g} \mathrm{~L}^{-1}$ i.a. de tiodicarbe.

A semeadura das forrageiras foi realizada simultaneamente à do milho, tendo-se utilizado outra semeadora-adubadora, com mecanismo sulcador do tipo disco duplo desencontrado, para SPD. As sementes foram acondicionadas no compartimento do fertilizante da semeadora e depositadas na profundidade de $0,08 \mathrm{~m}$, abaixo das sementes de milho, conforme recomendado por Kluthcouski et al. (2000), tendo sido espaçadas em $0,34 \mathrm{~m}$, com aproximadamente 532 pontos de valor cultural (VC) por hectare $\left(7 \mathrm{~kg} \mathrm{ha}^{-1}\right.$ de sementes puras viáveis com $\mathrm{VC}$ de $76 \%$ ).

A emergência do milho ocorreu em 25/11/2008, enquanto os capins emergiram em 29/11/2008, em razão da sua maior profundidade de deposição no solo, em comparação às sementes de milho. Quando a cultura do milho atingiu o estádio fenológico V4 (quatro folhas totalmente desenvolvidas), procedeu-se à adubação de cobertura, tendo-se aplicado, manualmente, a lanço, as doses de 50, 100, 150 e $200 \mathrm{~kg} \mathrm{ha}^{-1}$ de N. A adubação de cobertura foi realizada próxima às linhas do milho, tendo-se utilizado a ureia como fonte $(45 \%$ de N), e, após a adubação, foi feita irrigação da área experimental, o que evitou perdas excessivas de $\mathrm{N}$ por volatilização.

No período do florescimento, após a emissão da inflorescência feminina, determinaram-se as leituras indiretas do teor foliar de clorofila (índice de clorofila 
Falker, ICF) com clorofilômetro digital CFL 1030, (Falker, Porto Alegre, RS). As leituras foram realizadas no terço médio das folhas da base da espiga, tendo-se utilizado, em média, dez folhas por parcela (Malavolta et al., 1997). Para a diagnose foliar, o terço médio das dez folhas avaliadas foi coletado e utilizado na determinação das concentrações de N, P, K, Ca, Mg e S (Malavolta et al., 1997).

A colheita manual do milho, para avaliação dos componentes da produção e da produtividade de grãos (área útil da parcela), foi realizada em 25/3/2009, o que correspondeu a 121 dias após a emergência (DAE) do milho. Um dia após a colheita do milho, foram realizadas amostragens para determinação da produtividade de matéria seca (PMS) das braquiárias em consórcio. Em seguida, coletou-se a vegetação em $1 \mathrm{~m}^{2}$, em pontos dentro de cada unidade experimental, com auxílio de quadrado de metal $(1,0 \times 1,0 \mathrm{~m})$, tendose adotado, como referência, $0,05 \mathrm{~m}$ em relação à superfície do solo, para determinação da massa de matéria seca residual (palha). Em cada uma das amostragens, o material cortado foi pesado, e a amostra foi colocada em estufa de ventilação forçada de ar a $65^{\circ} \mathrm{C}$ até massa constante, para a quantificação da PMS (extrapolada para $\mathrm{kg} \mathrm{ha}^{-1}$ ).

Para a instalação e a condução do experimento na safra de 2009/2010, foram adotados os mesmos procedimentos descritos anteriormente para a safra de 2008/2009. Para tanto, a semeadura do milho e das espécies forrageiras foi realizada em 4/11/2009. A colheita do milho (safra de 2009/2010) ocorreu em 11/3/2010, o que correspondeu, também, a 121 DAE.

Os atributos referentes ao milho e às braquiárias tiveram os resultados submetidos à análise de variância pelo teste $\mathrm{F}$, a $5 \%$ de probabilidade, e as médias comparadas pelo teste t de Student, a 5\% de probabilidade, em função da espécies forrageiras. $\mathrm{O}$ efeito de doses de $\mathrm{N}$ no consórcio foi avaliado por análise de regressão polinomial. Todos os cálculos foram realizados com uso do programa SISVAR (Ferreira, 2011).

\section{Resultados e Discussão}

Não houve interação entre os atributos avaliados em nenhuma variável analisada durante a condução do experimento. Assim, pode-se inferir que as espécies forrageiras influenciaram somente os teores foliares de
N e S, na safra de 2008/2009, e de P, K e Ca na safra de 2009/2010, na cultura do milho (Tabela 1).

Os teores nutricionais foliares da cultura do milho foram maiores no consórcio com $U$. brizantha 'Xaraés', em comparação a U. ruziziensis. Isso indica que $U$. brizantha apresentou menor competição com a cultura do milho até o florescimento, período da coleta de folhas para análise. Portanto, somente os teores de N e $\mathrm{S}$ ficaram abaixo dos valores considerados adequados (Malavolta et al., 1997).

De acordo com Borghi \& Crusciol (2007), em virtude da grande exigência de $\mathrm{N}$ por ambas as espécies quando consorciadas simultaneamente, pode haver competição pelo nutriente, o que foi verificado no presente trabalho, em que o consórcio com $U$. ruziziensis resultou em menores teores de nutrientes foliares à cultura do milho.

Tabela 1. Teores de nutrientes foliares e índice de clorofila Falker (ICF) em folhas de milho, em função do consórcio com espécies de braquiárias (Urochloa brizantha 'Xaraés' e U. ruziziensis) e da adubação nitrogenada em cobertura, nas safras de 2008/2009 e 2009/2010 $0^{(1)}$.

\begin{tabular}{|c|c|c|c|c|c|c|c|}
\hline \multirow[t]{3}{*}{ Tratamentos } & $\mathrm{N}$ & $\mathrm{P}$ & K & $\mathrm{Ca}$ & $\mathrm{Mg}$ & $\mathrm{S}$ & \multirow[t]{2}{*}{ ICF } \\
\hline & \multicolumn{6}{|c|}{ 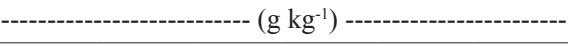 } & \\
\hline & \multicolumn{7}{|c|}{ Safra de $2008 / 2009$} \\
\hline Espécies & * & ns & ns & ns & ns & $* *$ & $* *$ \\
\hline U. brizantha & $27,8 \mathrm{a}$ & 5,8 & 19,7 & 3,6 & 2,3 & $1,03 \mathrm{a}$ & $65,9 \mathrm{a}$ \\
\hline U. ruziziensis & $25,7 \mathrm{~b}$ & 5,4 & 19,1 & 3,8 & 2,3 & $0,78 \mathrm{~b}$ & $60,5 \mathrm{~b}$ \\
\hline $\mathrm{N}\left(\mathrm{kg} \mathrm{ha}^{-1}\right)$ & $*$ & ns & ns & ns & ns & ns & $* *$ \\
\hline 0 & $23,6^{(2)}$ & 5,2 & 19,2 & 3,7 & 2,4 & 0,82 & $53,9^{(3)}$ \\
\hline 50 & 26,5 & 5,8 & 19,7 & 3,9 & 2,5 & 0,94 & 61,6 \\
\hline 100 & 27,4 & 5,7 & 19,6 & 3,7 & 2,2 & 0,92 & 63,5 \\
\hline 150 & 27,5 & 5,8 & 19,4 & 3,8 & 2,3 & 0,91 & 65,7 \\
\hline 200 & 28,7 & 5,6 & 19,0 & 3,5 & 2,2 & 0,95 & 71,2 \\
\hline \multirow[t]{2}{*}{ CV (\%) } & 11,23 & 11,34 & 6,51 & 15,37 & 15,82 & 16,30 & 7,05 \\
\hline & \multicolumn{7}{|c|}{ Safra de $2009 / 2010$} \\
\hline Espécies & ns & $* *$ & $* *$ & $* *$ & ns & ns & $*$ \\
\hline U. brizantha & 26,3 & $7,4 \mathrm{a}$ & $19,2 \mathrm{a}$ & $3,4 \mathrm{a}$ & 2,4 & 1,01 & $51,9 \mathrm{a}$ \\
\hline U. ruziziensis & 25,7 & $6,9 \mathrm{~b}$ & $18,4 \mathrm{~b}$ & $3,0 \mathrm{~b}$ & 2,2 & 1,05 & $48,6 \mathrm{~b}$ \\
\hline $\mathrm{N}\left(\mathrm{kg} \mathrm{ha}^{-1}\right)$ & $* *$ & $* *$ & ns & ns & ns & $* *$ & $* *$ \\
\hline 0 & $20,6^{(4)}$ & $6,3^{(5)}$ & 19,1 & 3,2 & 2,3 & $0,95^{(6)}$ & $39,9^{(7)}$ \\
\hline 50 & 24,9 & 6,9 & 18,9 & 3,2 & 2,2 & 0,97 & 50,3 \\
\hline 100 & 26,9 & 7,3 & 18,8 & 3,3 & 2,4 & 1,06 & 52,3 \\
\hline 150 & 28,4 & 7,6 & 18,7 & 3,3 & 2,3 & 1,09 & 52,8 \\
\hline 200 & 29,3 & 7,5 & 18,5 & 3,2 & 2,4 & 1,07 & 56,2 \\
\hline$\overline{C V}(\%)$ & 9,31 & 9,95 & 5,11 & 9,18 & 13,47 & 8,49 & 8,91 \\
\hline
\end{tabular}

${ }^{(1)}$ Médias seguidas de letras iguais, nas colunas, não diferem, entre si

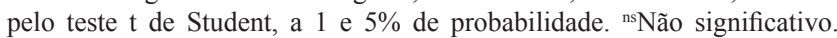
${ }^{(2)} \mathrm{N}$ foliar $=24,5+0,0225 \mathrm{~N}\left(\mathrm{R}^{2}=0,844 * *\right) \cdot{ }^{(3)} \mathrm{ICF}=55,4+0,0773 \mathrm{~N}$ $\left(\mathrm{R}^{2}=0,939 * *\right) \cdot{ }^{(4)} \mathrm{N}$ foliar $=21,84+0,0418 \mathrm{~N}\left(\mathrm{R}^{2}=0,913 * *\right)$. ${ }^{(5)} \mathrm{P}$ foliar $=6,19+0,31 \mathrm{~N}\left(\mathrm{R}^{2}=0,852 * *\right) \cdot{ }^{(6)} \mathrm{S}$ foliar $=0,92+0,036 \mathrm{~N}$ $\left(\mathrm{R}^{2}=0,843 * *\right) \cdot{ }^{(7)} \mathrm{ICF}=43,28+0,0782 \mathrm{~N}\left(\mathrm{R}^{2}=0,807 * *\right)$. 
Apesar de os teores de S nas folhas terem ficado abaixo do recomendado, não se observaram sintomas visuais de deficiência deste nutriente nas plantas. Os baixos teores de $\mathrm{S}$ nas folhas foram ocasionados, em parte, pela não aplicação de fontes alternativas deste nutriente no solo e pelo uso contínuo somente de ureia como fonte de $\mathrm{N}$, o que pode ter limitado as respostas nutricionais, em folhas de milho, à adubação nitrogenada em cobertura.

As leituras do ICF com clorofilômetro também foram influenciadas pelas espécies de braquiárias utilizadas, com valores que variam de 53,8 a 71,2 e de 48,63 a 51,97, nas duas safras analisadas, respectivamente (Tabela 1). Não houve efeito significativo das braquiárias sobre os teores de $\mathrm{N}, \mathrm{Mg}$ e $\mathrm{S}$ (safra de 2009/2010), nutrientes com função direta na atividade fotossintética, principalmente $\mathrm{N}$ e $\mathrm{Mg}$. No entanto, a espécie $U$. brizantha 'Xaraés' proporcionou maiores valores, que se refletiram sobre as leituras do ICF, já que estes nutrientes são participantes da molécula de clorofila.

Os resultados das leituras do ICF, na safra de 2008/2009, estão, em sua maioria, acima dos 55-58 considerados, por Malavolta et al. (1997), como adequados para o mesmo estádio de desenvolvimento da cultura e dos 62,8 e 59,5 obtidos por Rambo et al. (2008), em dois anos de avaliação, com aplicação de até $300 \mathrm{~kg} \mathrm{ha}^{-1}$ de N (20\% na semeadura e o restante em cobertura no estádio V3 da cultura do milho). Assim, os ICF encontrados no presente trabalho, na safra de 2008/2009, podem ser considerados elevados. Além disso, conforme Malavolta et al. (1997), para atingir $100 \%$ de colheita relativa de grãos da cultura do milho seria necessário em torno de 53,83 SPAD, que correspondem a 63,83 de ICF.

Os valores de ICF, para a safra de 2009/2010, ficaram abaixo do recomendado para a cultura do milho. Cabe ressaltar que a análise de correlação linear simples, entre os atributos avaliados no presente trabalho, indicou correlações diretas entre: leituras de ICF e teores de $\mathrm{N}$ foliar no milho $\left(\mathrm{R}^{2}=0,817 ; \mathrm{p}<0,01\right)$, $\mathrm{N}$ foliar e produtividade de grãos $\left(\mathrm{R}^{2}=0,751 ; \mathrm{p}<0,01\right)$, e ICF e produtividade de grãos $\left(\mathrm{R}^{2}=0,807 ; \mathrm{p}<0,01\right)$. Portanto, essas correlações auxiliarão na obtenção de equações para interpretação, em estudos futuros, do uso do clorofilômetro portátil, para recomendação da adubação nitrogenada em cobertura, para o milho.

As doses crescentes de $\mathrm{N}$ aplicadas em cobertura (2008/2009) influenciaram apenas os teores de $\mathrm{N}$ foliares e os valores do ICF, com aumento linear em função das doses (Tabela 1). Esse comportamento indica que, como o $\mathrm{N}$ faz parte da molécula de clorofila, o aumento de $\mathrm{N}$ foliar se reflete diretamente na leitura do ICF, que, no presente trabalho, apresentou correlação positiva $\left(\mathrm{R}^{2}=0,745 ; \mathrm{p}<0,01\right)$.

$\mathrm{Na}$ safra de 2009/2010, as doses de $\mathrm{N}$ em cobertura apresentaram ajustes lineares crescentes para os teores foliares de N, P e S, bem como para as leituras do ICF do clorofilômetro (Tabela 1). Estes resultados são indicativos da importância do $\mathrm{N}$ na nutrição da cultura do milho em consórcio com as braquiárias, principalmente em safra de verão com altas precipitações pluviais, entre novembro de 2009 e janeiro de 2010 (Figura 1), o que aumenta os riscos de perda de $\mathrm{N}$ por lixiviação. Novamente, pode-se observar que o incremento do $\mathrm{N}$ foliar resultou em maiores leituras do ICF, uma vez que este nutriente é primordial na constituição da clorofila. Assim, ao se considerar que, no consórcio, pode ocorrer competição por $\mathrm{N}$ entre a planta produtora de grãos e a forrageira, o manejo adequado da adubação nitrogenada deve atender a demanda pelo elemento nos estádios cruciais das espécies consorciadas, sem prejudicar a produtividade de ambas. Neste contexto, Argenta et al. (2002) destacaram a possibilidade de se inferir sobre o estado nutricional de $\mathrm{N}$, em milho, a partir de leituras com clorofilômetro.

O crescimento da planta de milho não foi influenciado pelas espécies de braquiária (Tabela 2). $O$ estande final de plantas (EFP) de milho não sofreu interferência do consórcio e da adubação nitrogenada, nas duas safras em estudo, diferentemente dos resultados obtidos por Borghi \& Crusciol (2007), que verificaram diminuição no EFP para o mesmo espaçamento entrelinhas utilizado no presente trabalho $(0,90 \mathrm{~m})$, em razão da maior competição exercida pelo capim, principalmente no período inicial de desenvolvimento do milho, e da maior população de $U$. brizantha 'Marandu' proporcionada pelo consórcio simultâneo na entrelinha da cultura produtora de grãos. Entretanto, no presente trabalho, não houve competição inicial das braquiárias com a cultura do milho, o que pode ser explicado pela excelente germinação e emergência da cultura do milho, que ocorreu antes da emergência das espécies de braquiária, semeadas a uma maior profundidade que o milho, para evitar maiores problemas com competição no período de desenvolvimento inicial das culturas. 
No geral, o crescimento da planta de milho também não foi influenciado pelos consórcios na safra de 2009/2010, exceto para altura de plantas (ALTP) e número de espigas por hectare (NE) (Tabela 2). Mesmo sem variação do EFP, a competição de $U$. ruziziensis com o milho resultou em plantas de menor estatura e com menor número de espigas por hectare; contudo, este componente da produção não resultou em menor produtividade de grãos, pois esta depende do efeito sinérgico sobre todos os demais componentes da produção (Tabela 3). Estes resultados assemelhamse aos de Pariz et al. (2011a), os quais relataram que $U$. ruziziensis proporcionou menor desenvolvimento e redução nos componentes de produção; porém, com reflexo na produtividade de grãos de milho, em comparação ao consórcio com outras espécies de braquiária.

Tabela 2. Estande final de plantas (EFP), número de espigas (NE), altura de plantas (ALTP), altura de inserção da espiga principal (AIEP) e diâmetro basal do colmo (DBC) de plantas de milho em função do consórcio com espécies de braquiárias (Urochloa brizantha 'Xaraés' e U. ruziziensis) e da adubação nitrogenada em cobertura, nas safras de 2008/2009 e 2009/2010 ${ }^{(1)}$.

\begin{tabular}{|c|c|c|c|c|c|}
\hline Tratamentos & $\begin{array}{c}\text { EFP } \\
(\text { plantas ha-1) }\end{array}$ & $\begin{array}{c}\text { NE } \\
(\text { espigas ha-1) }\end{array}$ & $\begin{array}{l}\text { ALTP } \\
(\mathrm{m})\end{array}$ & $\begin{array}{l}\text { AIEP } \\
(\mathrm{m})\end{array}$ & $\begin{array}{l}\mathrm{DBC} \\
(\mathrm{mm})\end{array}$ \\
\hline & \multicolumn{5}{|c|}{ Safra de $2008 / 2009$} \\
\hline Espécies & $\mathrm{ns}$ & ns & ns & ns & $\mathrm{ns}$ \\
\hline U. brizantha & 52.111 & 52.111 & 2,76 & 1,40 & 25,2 \\
\hline U. ruziziensis & 51.387 & 51.778 & 2,72 & 1,41 & 24,7 \\
\hline $\mathrm{N}\left(\mathrm{kg} \mathrm{ha}^{-1}\right)$ & ns & ns & ns & ns & ns \\
\hline 0 & 51.994 & 51.667 & 2,72 & 1,40 & 25,0 \\
\hline 50 & 50.556 & 51.528 & 2,77 & 1,45 & 24,3 \\
\hline 100 & 51.806 & 52.639 & 2,72 & 1,41 & 25,1 \\
\hline 150 & 52.917 & 52.917 & 2,73 & 1,38 & 25,4 \\
\hline 200 & 51.580 & 50.972 & 2,76 & 1,39 & 25,0 \\
\hline \multirow[t]{2}{*}{$\mathrm{CV}(\%)$} & 8,93 & 8,51 & 3,26 & 4,42 & 5,91 \\
\hline & \multicolumn{5}{|c|}{ Safra de $2009 / 2010$} \\
\hline Espécies & ns & $* *$ & $* *$ & ns & ns \\
\hline U. brizantha & 57.993 & $56.611 \mathrm{a}$ & $2,36 \mathrm{a}$ & 1,23 & 21,4 \\
\hline U. ruziziensis & 56.982 & $53.074 b$ & $2,29 b$ & 1,16 & 21,7 \\
\hline $\mathrm{N}\left(\mathrm{kg} \mathrm{ha}^{-1}\right)$ & ns & ns & ns & ns & ns \\
\hline 0 & 58.009 & 53.241 & 2,33 & 1,16 & 21,1 \\
\hline 50 & 57.593 & 54.120 & 2,33 & 1,16 & 21,0 \\
\hline 100 & 58.333 & 54.398 & 2,29 & 1,17 & 21,6 \\
\hline 150 & 56.667 & 55.602 & 2,36 & 1,27 & 21,3 \\
\hline 200 & 56.833 & 56.852 & 2,32 & 1,20 & 22,5 \\
\hline CV (\%) & 7,89 & 5,81 & 4,13 & 10,25 & 7,84 \\
\hline
\end{tabular}

Observou-se que, por efeito das doses de $\mathrm{N}$ em cobertura nas duas safras, não houve ajustes de regressões para as variáveis analisadas e influência no desenvolvimento das plantas de milho (Tabela 2).

Os resultados de altura de plantas (AP) e diâmetro basal do colmo (DBC), na consorciação do milho com espécies de braquiária, são indicativos da homogeneidade do híbrido de milho avaliado no presente trabalho. Resultados semelhantes foram obtidos por Borghi et al. (2008), que também não verificaram interação dos consórcios com as doses de $\mathrm{N}$, para esses atributos.

Tabela 3. Comprimento de espigas (CE), número de fileiras (NF), de grãos por fileira (NGF), de grãos por espiga (NGE), massa de cem grãos (M100), produtividade de grãos (PG) de milho e produtividade de matéria seca da parte aérea (PMS) das espécies de braquiárias (Urochloa brizantha 'Xaraés' e U. ruziziensis) em função do consórcio e da adubação nitrogenada em cobertura, nas safras de 2008/2009 e $2009 / 2010^{(1)}$.

\begin{tabular}{|c|c|c|c|c|c|c|c|}
\hline Tratamentos & $\begin{array}{c}\mathrm{CE} \\
(\mathrm{cm})\end{array}$ & $\mathrm{NF}$ & NGF & NGE & $\begin{array}{c}\text { M100 } \\
(\mathrm{g})\end{array}$ & $\begin{array}{c}\text { PG } \\
\left(\mathrm{kg} \mathrm{ha}^{-1}\right)\end{array}$ & $\begin{array}{c}\text { PMS } \\
\left(\mathrm{kg} \mathrm{ha}^{-1}\right)\end{array}$ \\
\hline & \multicolumn{7}{|c|}{ Safras de $2008 / 2009$} \\
\hline Espécies & $* *$ & ns & ns & ns & $* *$ & ns & ns \\
\hline U. brizantha & $19,3 \mathrm{a}$ & 16,8 & 36,2 & 598 & $36,5 \mathrm{a}$ & 7.571 & 6.000 \\
\hline U. ruziziensis & $18,2 \mathrm{~b}$ & 16,8 & 35,8 & 603 & $34,6 b$ & 6.607 & 5.600 \\
\hline $\mathrm{N}\left(\mathrm{kg} \mathrm{ha}^{-1}\right)$ & ns & ns & ns & ns & ** & ns & ns \\
\hline 0 & 18,2 & 16,7 & 33,4 & 557 & $33,5^{(2)}$ & 6.292 & 5.575 \\
\hline 50 & 18,9 & 16,7 & 37,5 & 626 & 35,9 & 7.594 & 5.675 \\
\hline 100 & 18,6 & 16,4 & 35,6 & 571 & 35,3 & 7.084 & 6.050 \\
\hline 150 & 19,3 & 17,3 & 35,9 & 622 & 36,5 & 6.512 & 5.950 \\
\hline 200 & 18,7 & 16,7 & 37,4 & 628 & 36,3 & 7.963 & 5.900 \\
\hline \multirow[t]{2}{*}{$\mathrm{CV}(\%)$} & 6,14 & 2,74 & 7,31 & 6,63 & 4,71 & 24,35 & 26,94 \\
\hline & \multicolumn{7}{|c|}{ Safra de $2009 / 2010$} \\
\hline Espécies & $\mathrm{ns}$ & $\mathrm{ns}$ & ns & ns & $\mathrm{ns}$ & $\mathrm{ns}$ & ns \\
\hline U. brizantha & 15,7 & 16,4 & 32,7 & 536 & 33,0 & 6.683 & 5.650 \\
\hline U. ruziziensis & 15,5 & 16,3 & 31,6 & 515 & 33,6 & 6.011 & 4.995 \\
\hline $\mathrm{N}\left(\mathrm{kg} \mathrm{ha}^{-1}\right)$ & $* *$ & $*$ & $* *$ & $* *$ & $* *$ & $* *$ & ns \\
\hline 0 & $13,5^{(3)}$ & $15,87^{(4)}$ & $27,4^{(5)}$ & $435^{(6)}$ & $30,7^{(7)}$ & $3.940^{(8)}$ & 5.130 \\
\hline 50 & 14,6 & 16,20 & 30,3 & 491 & 32,3 & 5.183 & 5.255 \\
\hline 100 & 16,2 & 16,12 & 32,9 & 532 & 33,7 & 6.838 & 5.900 \\
\hline 150 & 16,8 & 16,93 & 34,7 & 589 & 33,8 & 7.428 & 5.420 \\
\hline 200 & 16,8 & 16,68 & 35,1 & 581 & 35,8 & 8.344 & 5.375 \\
\hline $\mathrm{CV}(\%)$ & 5,97 & 4,14 & 6,76 & 8,61 & 3,59 & 18,87 & 19,28 \\
\hline
\end{tabular}

${ }^{(1)}$ Médias seguidas de letras iguais, nas colunas, não diferem, entre si, pelo teste t de Student, a 1 e $5 \%$ de probabilidade. ns Não significativo. ${ }^{(2)} \mathrm{M} 100=34,3+0,0124 \mathrm{~N}\left(\mathrm{R}^{2}=0,66 * *\right) \cdot{ }^{(3)} \mathrm{CE}=11,37+2,24 \mathrm{~N}-0,23 \mathrm{~N}^{2}$ $\left(\mathrm{R}^{2}=0,98^{* *} ; \mathrm{PM}=48,7 \mathrm{~kg} \mathrm{ha}^{-1}\right) \cdot{ }^{(4)} \mathrm{NF}=15,71+0,21 \mathrm{~N}\left(\mathrm{R}^{2}=0,644^{* *}\right)$. ${ }^{(5)} \mathrm{NGF}=28,12+0,0396 \mathrm{~N}\left(\mathrm{R}^{2}=0,939 * *\right) \cdot{ }^{(6} \mathrm{NGE}=447,6+0,78 \mathrm{~N}$ $\left(\mathrm{R}^{2}=0,919^{* *}\right) \cdot{ }^{(7)} \mathrm{M} 100=30,92+0,0234 \mathrm{~N}\left(\mathrm{R}^{2}=0,949 * *\right) \cdot{ }^{(8)} \mathrm{PG}=4136,00$ $+22,1062 \mathrm{~N}\left(\mathrm{R}^{2}=0,974 * *\right)$. 
Estes resultados de $\mathrm{AP}$ e $\mathrm{DBC}$ são importantes do ponto de vista da capacidade de translocação de nutrientes para as espigas. Colmos grossos, como os obtidos no presente trabalho, tornam-se mais resistentes ao tombamento pela ação do vento, das chuvas e do trânsito de máquinas e implementos (adubação de cobertura, aplicação de defensivos e colheita de grãos), o que mostra a viabilidade do consórcio do milho com espécies de braquiária. Vale ressaltar, ainda, que plantas maiores normalmente acumulam mais nutrientes, que são translocados para as espigas na época de enchimento dos grãos, e, após a colheita, estas depositam maior quantidade de palha na superfície do solo, o que é favorável para o SPD. Este fato pode ser atribuído ao histórico da área, que se encontrava há oito anos em SPD, na época das avaliações, possivelmente já com alguma mineralização de $\mathrm{N}$ em relação à imobilização desse nutriente pelos resíduos vegetais integrantes da palhada (Anghinoni, 2007). A homogeneidade dos valores médios de altura de inserção da espiga principal (AIE) (Tabela 2) também pode favorecer a colheita mecanizada, com diminuição nas perdas de espigas não colhidas pela plataforma da colhedora.

O comprimento de espigas (CE) e a massa de cem grãos (M100) foram os únicos componentes da produção influenciados pelos consórcios na safra de 2008/2009 (Tabela3). Na safra de 2009/2010, não foram constatadas diferenças nos componentes da produção e na produtividade de grãos da cultura do milho entre as espécies analisadas. A presença de espigas menores na consorciação do milho com U. ruziziensis pode ser explicada pela maior capacidade de competição com a cultura produtora de grãos, quando comparada a $U$. brizantha 'Xaraés', uma vez que $U$. ruziziensis tem hábito de crescimento mais prostrado e ocupa rapidamente o solo. Essa competição pode comprometer a translocação de fotoassimilados para os grãos e, consequentemente, afetar os componentes da produção.

Geralmente, $U$. brizantha, cultivar Marandu, apresenta maior competição com a cultura do milho, em comparação a $U$. ruziziensis (Pariz et al., 2009; Chioderoli et al., 2010). Porém, na literatura, também foram observados resultados de maior competição de U. ruziziensis (Pariz et al., 2011a). Assim, destacase que, além da espécie de $U$. brizantha, deve-se levar em consideração a cultivar utilizada (Marandu, Xaraés ou Piatã), visto que estas apresentam diferentes comportamentos quando consorciadas com a cultura do milho (Leonel et al., 2009). Portanto, outras avaliações mais específicas relacionadas à arquitetura das plantas em consórcio também podem definir, com mais clareza, o efeito da competição entre as espécies, sendo que, em geral, a capacidade de interceptação da radiação incidente está relacionada ao índice de área foliar (Amaral Filho et al., 2005). Além disso, fatores como envergadura da folha, desfolhamento, deficiência de nutrientes e condições de estresse das plantas por deficits hídricos comprometem os processos fisiológicos da planta.

A adubação nitrogenada afetou somente a massa de cem grãos (M100) na safra de 2008/2009, tendo apresentado resposta linear crescente, sem influência nos demais componentes da produção e na produtividade do milho (Tabela 3). Provavelmente, este fato pode ser atribuído ao histórico de oito anos em SPD da área e ao cultivo antecessor de feijão de inverno nas duas safras, tendo ocorrido, possivelmente, alguma mineralização de $\mathrm{N}$ pelos resíduos vegetais, $\mathrm{o}$ que forneceu este nutriente, de maneira satisfatória, ao desenvolvimento da cultura produtora de grãos e das plantas forrageiras. Contudo, o aumento neste componente da produção não resultou em aumento de produtividade de grãos, uma vez que esta depende da interação de todos os componentes da produção.

A produtividade de grãos ( $\mathrm{PG}$ ) de milho também não foi influenciada pelas espécies de braquiária, o que indica que a competição existente no consórcio não prejudicou este atributo, tendo em vista as altas produtividades obtidas neste sistema de produção. Alguns autores relataram que a presença de determinadas forrageiras também não afetou a produtividade de grãos de milho, em comparação ao seu cultivo isolado (Jakelaitis et al., 2005; Borghi \& Crusciol, 2007; Pariz et al., 2009). Porém, em alguns casos, houve necessidade da aplicação de herbicida nicosulfuron, em subdoses, para reduzir o crescimento da forrageira, como forma de garantir o pleno desenvolvimento do milho, o que não foi feito no presente trabalho. Kluthcouski et al. (2000), ao avaliar a produtividade de grãos de 18 híbridos de milho em consórcio com forrageiras na estação chuvosa, em diferentes locais, concluíram que, em geral, a competição interespecífica não reduziu significativamente a produtividade de grãos. Estes autores também verificaram que, na maioria dos locais, houve tendência ao aumento de 
produtividade no sistema consorciado, provavelmente em função da não aplicação de herbicida graminicida em pós-emergência, o que reduziu possíveis efeitos fitotóxicos.

Na safra de 2009/2010, os componentes da produção e a produtividade de grãos apresentaram efeito das doses de $\mathrm{N}$ em cobertura (Tabela 3 ). Os componentes, número de fileiras (NF), grãos por fileira (NGF) e grãos por espiga (NGE), estão diretamente associados e apresentaram o mesmo comportamento linear crescente em função das doses de $\mathrm{N}$ em cobertura, o que mostra o papel fundamental deste nutriente para a formação dos grãos de milho na espiga. Este comportamento linear crescente pode ser atribuído à competição com as forrageiras e aos altos valores de precipitação pluvial (Figura 1), o que pode ter acelerado as perdas de $\mathrm{N}$ por lixiviação. Os demais componentes da produção e a produtividade de grãos também apresentaram ajustes lineares crescentes com as doses de $\mathrm{N}$ em cobertura. Houve considerável redução nos valores dos componentes da produção e da produtividade de grãos de milho na ausência de $\mathrm{N}$ e na dose de $50 \mathrm{~kg} \mathrm{ha}^{-1}$, na safra de 2009/2010, em comparação à safra de 2008/2009. Como as parcelas foram alocadas nos mesmos locais, em ambos os anos, pode-se inferir que a não ou a baixa utilização de adubação nitrogenada compromete a cultura do milho cultivada em consórcio com braquiárias ao longo de dois anos, por se tratar de duas gramíneas altamente exigentes em N.

Lara-Cabezas \& Pádua (2007) avaliaram a dinâmica do N no sistema consorciado de ILP e não observaram respostas positivas do milho às doses de $\mathrm{N}$, em cultivo exclusivo ou consorciado com braquiária. Portanto, não houve diferenças na produtividade entre os tratamentos, como verificado no presente trabalho para a safra de 2008/2009. Já Batista et al. (2011), ao avaliar o consórcio da cultura do milho safrinha com espécies de braquiária, verificaram efeito da adubação nitrogenada em cobertura sobre a produtividade de grãos em apenas um local avaliado. Estes resultados são indicativos da importância de se realizar mais pesquisas sobre a adubação nitrogenada, nestes sistemas de produção, visto que, possivelmente, esta é influenciada por condições climáticas, época do ano, modos de consorciação, espécies forrageiras utilizadas e tempo de adoção do SPD.

Com relação à produtividade de massa seca (PMS) das braquiárias após a colheita do milho, não houve diferenças significativas entre as espécies e o efeito da adubação nitrogenada em cobertura na cultura do milho (Tabela 3). Porém, as quantidades entre $5.000 \mathrm{e}$ $6.000 \mathrm{~kg}$ de matéria seca por hectare mostram o grande potencial deste sistema de produção, o que garante forragem para o fornecimento à alimentação animal, uma vez que, após a colheita da cultura granífera, a pastagem já estava estabelecida para utilização do outono à primavera. Posteriormente, a dessecação possibilita formação de palhada e continuidade do SPD, pois estas espécies garantem boa cobertura do solo e ótima reciclagem de nutrientes. Quantidades médias de $12 \mathrm{Mg} \mathrm{ha}^{-1}$ de palhada são frequentemente obtidas e proporcionam plena cobertura do solo, com boa espessura, principalmente quando o consórcio é feito com a cultura do milho (Crusciol et al., 2009).

Além disso, a eficiência no aproveitamento do N, nesse sistema de consórcio, pode ser comprovada na comparação com as menores PMS do monocultivo de capim-marandu adubado com $\mathrm{N}$ e submetido a corte no final da primavera/início do verão, conforme relatado por Benett et al. (2008), em condições climáticas semelhantes às do presente trabalho. Leonel et al. (2009) e Pariz et al. (2011a) também comprovaram a eficiência desse sistema, ao utilizar diferentes espécies de braquiária.

Portanto, o uso da consorciação de culturas é um dos meios para se elevar a produtividade de sistemas de produção integrados. Também é possível reduzir o custo da formação das pastagens e ofertar alimento para o gado no período de entressafra, em que a oferta de forragem é reduzida. Além disso, a ótima germinação e emergência dos capins proporcionaram ocupação homogênea da área, o que diminuiu a incidência de luz no solo e reduziu, ao longo do ciclo da cultura do milho, a incidência de plantas daninhas, sem a necessidade de utilização de herbicidas comumente empregados.

\section{Conclusões}

1. Os teores de nutrientes foliares e o índice de clorofila Falker (ICF) da cultura do milho consorciado com Urochloa ruziziensis, de modo geral, foram menores quando comparados aos valores obtidos no consórcio com U. brizantha, cultivar Xaraés, porém, sem comprometimento da produtividade de grãos.

2. A adubação nitrogenada em cobertura até a dose de $200 \mathrm{~kg} \mathrm{ha}^{-1}$ de $\mathrm{N}$ aumenta linearmente o ICF, os teores

Pesq. agropec. bras., Brasília, v.47, n.8, p.1038-1047, ago. 2012 
de N, P e S, bem como os componentes da produção e a produtividade de grãos da cultura do milho.

3. O sistema plantio direto garante quantidade acima de $5.000 \mathrm{~kg}$ de matéria seca por hectare, tanto para o fornecimento à alimentação animal quanto para a sustentabilidade e a continuidade do sistema plantio direto.

\section{Referências}

AMARAL FILHO, J.P.R. do; FORNASIERI FILHO, D.; FARINELLI, R.; BARBOSA, J.C. Espaçamento, densidade populacional e adubação nitrogenada na cultura do milho. Revista Brasileira de Ciência do Solo, v.29, p.467-473, 2005.

ANGHINONI, I. Fertilidade do solo e seu manejo em sistema plantio direto. In: NOVAIS, R.F.; ALVARES V., V.H.; BARROS, N.F. de; FONTES, R.L.F.; CANTARUTTI, R.B.; NEVES, J.C.L. (Ed.). Fertilidade do solo. Viçosa: Sociedade Brasileira de Ciência do Solo, 2007. p.873-928.

ARGENTA, G.; SILVA, P.R.F. da; MIELNICZUK, J.; BORTOLINI, C.G. Parâmetros de planta como indicadores do nível de nitrogênio na cultura do milho. Pesquisa Agropecuária Brasileira, v.37, p.519-527, 2002.

BALBINO, L.C.; BARCELlOS, A. de O.; STONE, L.F. (Ed.). Marco referencial: integração lavoura-pecuária-floresta. Brasília: Embrapa, 2011a. 130p.

BALBINO, L.C.; CORDEIRO, L.A.M.; PORFÍRIO-DA-SILVA, V.; MORAES, A. de; MARTÍNEZ, G.B.; ALVARENGA, R.C.; KICHEL, A.N.; FONTANELI, R.S.; SANTOS, H.P. dos; FRANCHINI, J.C.; GALERANI, P.R. Evolução tecnológica e arranjos produtivos de sistemas de integração lavoura-pecuária-floresta no Brasil. Pesquisa Agropecuária Brasileira, v.46, p.i-xii, 2011b. Prefácio.

BATISTA, K.; DUARTE, A.P.; CECCON, G.; DE MARIA, I.C.; CANTARELLA, H. Acúmulo de matéria seca e de nutrientes em forrageiras consorciadas com milho safrinha em função da adubação nitrogenada. Pesquisa Agropecuária Brasileira, v.46, p.1154-1160, 2011.

BENETT,C.G.S.;BUZETTI,S.;SILVA,K.S.;BERGAMASCHINE, A.F.; FABRICIO, J.A. Produtividade e composição bromatológica do capim-marandu a fontes e doses de nitrogênio. Ciência e Agrotecnologia, v.32, p.1629-1636, 2008.

BORGHI, E.; COSTA, N.V.; CRUSCIOL, C.A.C.; MATEUS, G.P. Influência da distribuição espacial do milho e da Brachiaria brizantha consorciados sobre a população de plantas daninhas em sistema plantio direto na palha. Planta Daninha, v.26, p.559-568, 2008.

BORGHI, E.; CRUSCIOL, C.A.C. Produtividade de milho, espaçamento e modalidade de consorciação com Brachiaria brizantha em sistema plantio direto. Pesquisa Agropecuária Brasileira, v.42, p.163-171, 2007.

CHIODEROLI, C.A.; MELLO, L.M.M. de; GRIGOLLI, P.J.; SILVA, J.O. da R.; CESARIN, A.L. Consorciação de braquiárias com milho outonal em plantio direto sob pivô central. Engenharia Agrícola, v.30, p.1101-1109, 2010.

CRUSCIOL, C.A.C.; MATEUS, G.P.; NASCENTE, A.S.; MARTINS, P.O.; BORGHI, E.; PARIZ, C.M. An innovative crop-forage intercrop system: early cycle soybean cultivars and palisadegrass. Agronomy Journal, v.104, p.1085-1095, 2012.

CRUSCIOL, C.A.C.; SORATTO, R.P.; BORGHI, E.; MATEUS, G.P. Integração lavoura-pecuária: benefícios das gramíneas perenes nos sistemas de produção. Informações Agronômicas, n.125, p.2-15, 2009.

FERREIRA, D.F. Sisvar: a computer statistical analysis system. Ciência e Agrotecnologia, v.35, p.1039-1042, 2011.

JAKELAITIS, A.; SILVA, A.F.; SILVA, A.A.; FERREIRA, L.R.; FREITAS, F.C.L; VIANA, R.G. Influência de herbicidas e de sistemas de semeadura de Brachiaria brizantha consorciada com milho. Planta daninha, v.23, p.59-67, 2005.

KLUTHCOUSKI, J.; COBUCCI, T.; AIDAR, H.; YOKOYAMA, L.P.; OLIVEIRA, I.P. de; COSTA, J.L. da S.; VILELA, L; BARCELLOS, A. de O; MAGNABOSCO, C. de U. Sistema Santa Fé - tecnologia Embrapa: integração lavoura-pecuária pelo consórcio de culturas anuais com forrageiras, em áreas de lavoura, nos sistemas direto e convencional. Santo Antônio de Goiás: Embrapa Arroz e Feijão, 2000. 28p. (Embrapa Arroz e Feijão. Circular técnica, 38).

LARA-CABEZAS, W.A.R.; PÁDUA, R.V. de. Eficiência e distribuição de nitrogênio aplicado em cobertura na cultura de milho consorciada com Brachiaria ruziziensis, cultivada no sistema Santa Fé. Bragantia, v.66, p.131-140, 2007.

LEONEL, F. de P.; PEREIRA, J.C.; COSTA, M.G.; DE MARCO JÚNIOR, P.; LARA, L.A.; QUEIROZ, A.C. de. Comportamento produtivo e características nutricionais do capim-braquiária cultivado em consórcio com milho. Revista Brasileira de Zootecnia, v.38, p.177-189, 2009.

MACEDO, M.C.M. Integração lavoura e pecuária: o estado da arte e inovações tecnológicas. Revista Brasileira de Zootecnia, v.38, p.133-146, 2009.

MALAVOLTA, E.; VITTI, G.C.; OLIVEIRA, S.A. Avaliação do estado nutricional das plantas: princípios e aplicações. 2.ed. Piracicaba: Associação Brasileira para Pesquisa da Potassa e do Fosfato, 1997. 319p.

MARTHA JÚNIOR, G.B.; CORSI, M.; TRIVELIN, P.C.O.; VILELA, L. Recuperação de ${ }^{15} \mathrm{~N}$-ureia no sistema solo-planta de pastagem de capim-tanzânia. Revista Brasileira de Ciência do Solo, v.33, p.95-101, 2009.

PARIZ, C.M.; ANDREOTTI, M.; AZENHA, M.V.; BERGAMASCHINE, A.F.; MELLO, L.M.M. de; LIMA, R.C. Produtividade de grãos de milho e massa seca de braquiárias em consórcio no sistema de integração lavoura-pecuária. Ciência Rural, v.41, p.875-882, 2011a.

PARIZ, C.M.; ANDREOTTI, M.; BERGAMASCHINE, A.F.; BUZETTI, S.; COSTA, N.R.; CAVALLINI, M.C.; ULIAN, N. de A.; LUIGGI, F.G. Yield, chemical composition and chlorophyll relative content of Tanzânia and Mombaça grasses irrigated and fertilized with nitrogen after corn intercropping. Revista Brasileira de Zootecnia, v.40, p.728-738, 2011 b. 
PARIZ, C.M.; ANDREOTTI, M.; BUZETTI, S.; BERGAMASCHINE, A.F.; ULIAN, N.A.; FURLAN, L.C.; MEIRELLES, P.R. de L.; CAVASANO, F.A. Straw decomposition of nitrogen-fertilized grasses intercropped with irrigated maize in an integrated crop-livestock system. Revista Brasileira de Ciência do Solo, v.35, p.2029-2037, 2011c.

PARIZ, C.M.; ANDREOTTI, M.; TARSITANO, M.A.A.; BERGAMASCHINE, A.F.; BUZETTI, S.; CHIODEROLI, C.A. Desempenhos técnicos e econômicos da consorciação de milho com forrageiras dos gêneros Panicum e Brachiaria em sistema de integração lavoura-pecuária. Pesquisa Agropecuária Tropical, v.39, p.360-370, 2009.

PARIZ, C.M.; FERREIRA, R.L.; SÁ, M.E. de; ANDREOTTI, M.; CHIODEROLI, C.A.; RIBEIRO, A.P. Qualidade fisiológica de sementes de Brachiaria e avaliação da produtividade de massa seca, em diferentes sistemas de integração lavoura-pecuária sob irrigação. Pesquisa Agropecuária Tropical, v.40, p.330-340, 2010.

RAMBO, L.; SILVA, P.R.F. da; STRIEDER, M.L.; DELATORRE, C.A.; BAYER, C.; ARGENTA, G. Adequação de doses de nitrogênio em milho com base em indicadores de solo e de planta. Pesquisa Agropecuária Brasileira, v.43, p.401-409, 2008.

RUFINO, M.C.; TTTTONELL, P.; REIDSMA, P.; LÓPEZ-RIDAURA， S.; HENGSDIJK, H.; GILLER, K.E.; VERHAGEN, A. Network analysis of $\mathrm{N}$ flows and food self-sufficiency - a comparative study of crop-livestock systems of the highlands of East and southern Africa. Nutrient Cycling in Agroecosystems, v.85, p.169-186, 2009.

SANTOS, H.G. dos; JACOMINE, P.K.T.; ANJOS, L.H.C. dos; OLIVEIRA, V.A. de; OLIVEIRA, J.B. de; COELHO, M.R.; LUMBRERAS, J.F.; CUNHA, T.J.F. da (Ed.). Sistema brasileiro de classificação de solos. 2.ed. Rio de Janeiro: Embrapa Solos, 2006. 306p.

SILVEIRA, P.M. da; BRAZ, A.J.B.P.; KLIEMANN, H.J.; ZIMMERMANN, F.J.P. Adubação nitrogenada no feijoeiro cultivado sob plantio direto em sucessão de culturas. Pesquisa Agropecuária Brasileira, v.40, p.377-381, 2005.

TRACY, B.F.; ZHANG, Y. Soil compaction, corn yield response, and soil nutrient pool dynamics within an integrated crop-livestock system in Illinois. Crop Science, v.48, p.1211-1218, 2008.

Recebido em 20 de abril de 2011 e aprovado em 20 de julho de 2012 